\title{
Immigració, unions mixtes i integració sociocultural: cap a una anàlisi complexa multimètode
}

\author{
Dan Rodríguez-García
}

Universitat Autònoma de Barcelona. Departament d'Antropologia Social i Cultural dan.rodriguez@uab.cat

Miguel Solana Solana

Universitat Autònoma de Barcelona. Departament de Geografia antoniomiguel.solana@uab.cat

\section{Verónica de Miguel Luken}

Universidad de Málaga. Departamento de Derecho de Estado y Sociología vdmiguel@uma.es

\section{Miranda J. Lubbers}

Universitat Autònoma de Barcelona. Departament d'Antropologia Social i Cultural mirandajessica.lubbers@uab.cat

\section{Resum}

Des de principis de la darrera dècada, coincidint amb la important arribada d'immigració estrangera a Espanya, les unions mixtes o binacionals han augmentat considerablement. Malgrat això, encara se sap ben poc sobre l'abast, les dinàmiques internes, els significats i les conseqüències d'aquesta realitat. En aquest article presentem els avenços de dos projectes de recerca en curs on s'està intentant clarificar la relació entre unions/llars mixtes i integració/cohesió social, a partir de l'estudi d'unions mixtes i no mixtes de set col-lectius immigrats residents a Catalunya, aplicant una aproximació multimètode (quantitativa i qualitativa), que inclou la explotació de fonts estadístiques administratives i l'anàlisi de 94 xarxes personals/socials. Les dades que presentem aquí corresponen a l'anàlisi d'una de les fonts estadístiques més significatives (ENI) i a l'anàlisi descriptiva d'alguns casos de xarxes personals. Tot apunta a una relació entre «mixicitat» $\mathrm{i}$ integració multidireccional o segmentada, més complexa del que tradicionalment s'ha teoritzat.

Paraules clau: immigració; unions mixtes; mixicitat; integració social; xarxes personals/ socials. 
Resumen. Inmigración, uniones mixtas e integración sociocultural en Cataluña: hacia un análisis complejo multimétodo

Desde principios de la última década, coincidiendo con la importante llegada de inmigración extranjera a España, las uniones mixtas o binacionales han aumentado considerablemente. Sin embargo, todavía se sabe muy poco sobre el alcance, las dinámicas internas, los significados y las consecuencias sociales de esta realidad. Presentamos aquí los avances de dos proyectos de investigación en curso donde se está intentando clarificar la relación entre uniones/hogares mixtos e integración/cohesión social, a partir del estudio de uniones mixtas y no mixtas de siete colectivos inmigrados residentes en Cataluña, aplicando una aproximación multimétodo que incluye la explotación de fuentes estadísticas administrativas y el análisis de 94 redes personales/sociales. Los datos que presentamos corresponden al análisis de una de las fuentes estadísticas más significativas (ENI) y al análisis descriptivo de algunos casos de redes personales. Todo apunta a una relación entre «mixicidad» e integración multidireccional o segmentada, más compleja de lo que tradicionalmente se ha teorizado.

Palabras clave: inmigración; uniones mixtas; mixicidad; integración social; redes personales/ sociales.

Résumé. Immigration, unions mixtes et intégration socioculturelle en Catalogne: vers une analyse complexe multi-méthode

Depuis le début de la dernière décennie, qui coïncide avec l'arrivée importante de l'immigration étrangère en Espagne, les mariages mixtes ou bi-nationaux ont considérablement augmenté. Cependant, on en sait encore très peu sur la dimension, la dynamique interne, les significations et les conséquences sociales de cette réalité. Nous présentons ici les résultats de deux projets de recherche en cours, où nous tentons de clarifier la relation entre unions mixtes et intégration/cohésion sociale à partir de l'étude de sept groupes d'immigrés en unions mixtes et non-mixtes résidant en Catalogne, ainsi qu'une approche multi-méthode qui comprend l'exploitation des sources de données statistiques et l'analyse de 94 réseaux personnels/sociaux. Les données présentées ici correspondent à l'analyse de l'une des sources statistiques les plus importantes (ENI) ainsi que de l'analyse descriptive de certains cas de réseaux personnels. Tout indique une relation entre mixité et intégration multidirectionnelle ou segmentée, plus complexe que ce qui a traditionnellement été théorisé.

Mots-clé: immigration; unions mixtes; mixité; intégration sociale; réseaux personnels/ sociaux.

Abstract. Immigration, intermarriage and socio-cultural integration in Catalonia, Spain: Towards a multi-method analysis

Since the beginning of the last decade, coinciding with the arrival of a considerable number of foreign immigrants to Spain, the amount of mixed or bi-national unions has grown considerably. However, very little is still actually known about the scope, internal dynamics, meanings and social consequences of this situation. In this paper we present the preliminary findings of two research projects in progress, in which the relationship between mixed unions and social integration/cohesion is being analyzed, from the study of seven immigrant origins forming mixed and non-mixed unions residing in Catalonia (Spain), and using a multi-method approach that includes the analysis of administrative data sources and $94 \mathrm{personal} / \mathrm{social}$ networks. The data presented here correspond to the 
analysis of one significant data source (ENI) and the descriptive analysis of some personal networks. Our results suggest a multi-directional or segmented relationship between mixedness and social integration, which is much more complex than it has traditionally been theorized.

Keywords: immigration; mixed unions; mixedness; social integration; personal/social networks.

\section{Sumari}
1. Introducció i context teòric: unions
3. Resultats mixtes i integració social
4. Conclusions
2. Objectius i metodologia
Referències bibliogràfiques

\section{Introducció i context teòric: unions mixtes i integració social}

L'estudi de les unions mixtes $i$, en general, de l'endogàmia i l'exogàmia (unions entre persones del mateix o diferent grup o categoria social, respectivament) ha despertat l'interès dels investigadors durant segles, des dels primers treballs dels antropòlegs evolucionistes del segle XIx (McLennan, Tylor, Morgan), passant pels estudis sociològics dels anys vint i trenta del segle passat de l'Escola de Chicago liderats per Robert Park, fins a l'actualitat, en què abunden els estudis des de diferents disciplines (antropologia, sociologia, demografia i geografia, principalment). I és així perquè l'encreuament de fronteres socials, ètniques, culturals, religioses o de classe a través de la unió de parella/matrimoni no només parla de les decisions individuals sinó que també revela l'abast de les divisions socials i les relacions entre els grups dins d'una societat; per tant, es tracta d'un test crucial per identificar l'estructura i dinàmica d'una societat (Davis, 1941; Merton, 1941; Leach, 1967).

Podem dir que les unions/famílies mixtes o binacionals i transnacionals han augmentat de forma molt significativa a tot el món en les últimes dècades, juntament amb la diversificació creixent de formes de família, a causa de la intensificació de la mobilitat i els processos de globalització i modernització, que impliquen una «internacionalització o transnacionalització de la intimitat» $\mathrm{i}$ de les relacions amoroses (King, 2002: 99; Beck i Beck-Gernsheim, 2012) i l'aparició de mercats matrimonials transnacionals (Bryceson i Vuorela, 2002; Constable, 2003; Waldis i Byron, 2006; Rodríguez-García, 2006, 2012; Rosenfeld, 2007; Scott i Cartledge, 2009; Mai i King, 2009; Heikkilä i Yeoh, 2010; Hull et al., 2010; Williams, 2010; Doo-Sub, 2012).

Dins d'aquest context, des de principis de la darrera dècada, coincidint amb una etapa d'important arribada d'immigració estrangera a Espanya (Izquierdo, 1996; Arango, 2000; Domingo, 2010), els matrimonis mixtos o binacionals (entre persones de nacionalitat espanyola i persones de nacionalitat estrangera, o entre persones nascudes a l'estranger i persones nascudes 
a Espanya) també han crescut exponencialment; en particular a Catalunya: del 5\% de les unions inscrites celebrades el 2000 al 24\% el 2009 (a Espanya el 5\% el 2000 i el 16\% el 2010), fins al 31\% al municipi de Barcelona el $2011^{1}$ (Idescat, 2009: 7; INE, 2011a, 2011b: 3; i Ajuntament de Barcelona, 2012: 3,7 , respectivament).

L'estudi d'aquesta realitat a España ha augmentat paral.lelament a la seva incidència demogràfica durant els darrers anys, i en aquests moments ja disposem de contribucions molt valuoses en aquest terreny (Rodríguez-García, 2002, 2004a, 2004b, 2006, 2012; Cortina, Esteve i Domingo, 2006, 2008; Santacreu i Francés, 2008; Esteve y Bueno, 2010; Bueno, 2010; Roca Girona, 2011; Sánchez Domínguez, 2011, entre d'altres).

Malgrat tot això, encara se sap ben poc sobre l'abast, les dinàmiques internes, els significats i les conseqüències socials d'aquest fenomen. I atès que la integració/cohesió social és un dels majors desafiaments que afronten les societats modernes en l'actualitat, una pregunta d'investigació vital és precisament explorar la relació entre les unions mixtes, i la «mixicitat» ${ }^{2}$ en general, i la integració sociocultural dels immigrants i minories, especialment en contextos que han experimentat canvis importants en la seva estructura i composició demogràfica i sociocultural gràcies a la immigració internacional, com és el cas de Catalunya en els darrers anys.

Les unions mixtes s'han vist tradicionalment com un indicador clau (l'última fase) de la integració social o fins i tot de l'assimilació dels immigrants i les minories ètniques a la societat en general, perquè aquest tipus d'unions es pensa que faciliten l'assentament dels immigrants en la societat d'acollida, una major interacció i l'expansió de les seves xarxes socials, la permeabilitat de les fronteres socials i la disminució de la distància social, l’adquisició de capital social i l'erosió de les identitats ètniques i els prejudicis culturals (Resnik, 1933; Gordon, 1964; Alba i Kessler, 1979; Lieberson i Waters, 1988; Pagnini i Morgan 1990; Coleman, 1994; Rumbaut, 1997; Kalmijn, 1998; Qian i Litcher, 2001). Altres autors han qüestionat aquesta relació directa o sense matisos entre mixicitat i integració social i n'han emfasitzat la complexitat (Marcson, 1950; Lievens, 1999; Fu, 2001; Rodríguez-García, 2002, 2004a, 2004b, 2006, 2012; Safi, 2006, 2008; Santacreu i Francés, 2008; Song, 2009, 2010; Sánchez Domínguez, 2011; Ward 2013).

Per exemple, la unió mixta pot significar integració socioeconòmica per a uns grups i no per a uns altres, com ho demostren els estudis de Safi (2006, 2008) a França. Safi troba que entre els europeus, excepte en el cas dels portuguesos, sí que hi ha una relació entre exogàmia i inserció laboral; mentre que en altres grups (per exemple, els tunisians) no és així; i fins i tot pot ser a la

1. Cal tenir en compte que aquestes dades tenen diversos biaixos, que més endavant explicarem.

2. Aquest és un concepte que preferim al de mestissatge — que té connotacions més negatives lligades al passat colonial_-i que prové de l'anglès mixedness i del francès mixité, per emfasitzar la realitat processual, complexa i contestada del fenomen. 
inversa, com per exemple amb els asiàtics o portuguesos, entre els quals hi ha una major inserció laboral malgrat l'endogàmia o justament a causa d'aquesta.

D'altra banda, la unió mixta pot ser conseqüència d'una legislació restrictiva sobre el reagrupament familiar o es pot fer per facilitar l'obtenció del permís de residència o l'accés a la ciutadania al país d'acolliment. Els anomenats "matrimonis de conveniència» serien així, en part, una conseqüència d'aquest marc restrictiu (Rodríguez-García, 2004a: 84). En aquest sentit, és necessari distingir entre els efectes i les causes de la integració a través del matrimoni mixt, ja que l'exogàmia pot ser de fet una conseqüència de la desigualtat $o$ d'estructures socials excloents o limitadores de la integració social.

Tanmateix, l'exogàmia no pressuposa necessàriament l'erosió o absència de prejudicis cap a altres grups (Gordon, 1964; Alba i Kessler, 1979; Kalmijn, 1998: 396), com ja va assenyalar el treball clàssic de Roger Bastide (1961), especialment en contextos segmentats socialment i ètnicament. Els desequilibris de gènere en les unions mixtes moltes vegades es deuen justament a prejudicis culturals, a l'«exotització» històrica de diferents col-lectius i a l'intercanvi d'estatus social/ètnic en la unió. Veiem això, per exemple, amb l'exotització occidental de la negritud (Fanon, 1967; Rodríguez-García, 2004a: 140-149); o en la xenofília per les dones asiàtiques, a les quals històricament s'ha estereotipat amb atributs d'hiperfeminitat, seducció i submissió (Said, 1978; Lee, 2004; Rodríguez-García, 2007). En relació amb això, dins de les unions mixtes solen existir diferències que són el reflex justament d'estructures socioètniques estratificades. Segons les teories d'estratificació social, que relacionen la diferenciació social estructural (desigualtat) amb l'associació social desigual, allà on hi ha una jerarquia de prestigi de grups socials, que sembla que és universal, els patrons matrimonials segueixen la "línia de color» estratificada (Porter, 1965; Leach, 1967; Rytina et al., 1988). Les unions mixtes predominants, doncs, seran les formades per immigrants els nivells econòmics o educatius dels quals són més alts que els de les seves parelles no immigrants (Davis, 1941; Merton, 1941; per a una crítica vegeu Rosenfeld, 2005, i per a la contracrítica vegeu Rodríguez-García, 2007, i Kalmijm, 2010).

En relació amb aquest àmbit dels fenotips i dels estatus socioètnics, els descendents d'unions mixtes tampoc no estan necessàriament millor integrats a la societat on viuen si el seu fenotip els limita socialment (dissonància entre la pròpia identitat i la identitat imposada per la societat). L'estudi de Song i Aspinall (2012), per exemple, mostra que els fills de parelles mixtes de negres i blancs al Regne Unit solen identificar-se com a «mixtos», però la gent els considera i tracta com a «negres».

Finalment, l'endogàmia no equival necessàriament a un comportament tradicional i a una actitud de segregació en contraposició a l'exogàmia (Gordon, 1964). Com assenyalen diversos estudis (Lievens, 1999: 717; RodríguezGarcía, 2004a, 2004b, 2012: 47-48, Collet i Santelli, 2012: 290), l'endogàmia pot implicar perfectament modernitat i mobilitat social.

En tot cas, el nexe entre unions mixtes o mixicitat i integració social no és clar, i hi ha encara moltes preguntes per contestar: Hi ha avantatges pel fet de 
formar part d'una parella/família mixta o intercultural? Condueix l'exogàmia a una major integració sociocultural i a una mobilitat social ascendent per als immigrants o fills d'immigrants? Hi ha diferències en funció de factors com ara l'origen, el sexe, la classe social, l'edat/generació, la trajectòria migratòria o altres factors contextuals? Quins canvis es produeixen en la vida i el dia a dia d'una parella mixta (per exemple, en l'àmbit sociocultural, en quina mesura canvien els valors, les normes $i$ les pràctiques)? En quina mesura suposen les unions mixtes un desafiament de les nocions tradicionals d'origen, cultura, ètnia o fenotip? Pateixen els matrimonis mixtos i els seus descendents menys discriminació social que les formades només per immigrants? Quin paper tenen les parelles/famílies mixtes en l'erosió dels prejudicis socioculturals i en el foment de la inclusió? És la integració una causa o una conseqüència de la unió mixta?

En aquest treball presentem els avenços de dos projectes de recerca finançats en $\operatorname{curs}^{3}$ on s'intenta respondre aquestes preguntes entorn de la relació entre unions mixtes i integració social.

\section{Objectius i metodologia}

L'objectiu general del projecte en què s'inscriu aquest treball és investigar la relació entre mixicitat $\mathrm{i}$ integració/cohesió social a Catalunya a partir de l'estudi de les unions/famílies mixtes. Es tracta específicament de: 1) Mesurar la incidència $\mathrm{i}$ les característiques sociodemogràfiques de les unions mixtes a Catalunya en els darrers anys, especialment des de 2007, a través de diferents fonts de dades estadístiques; i 2) Mesurar l'efecte de les unions mixtes (variable independent) sobre la integració sociocultural (variable dependent), a través també de diferents fonts de dades i tècniques d'anàlisi i analitzant unions mixtes i no mixtes de diferents grups d'immigrants residents a Catalunya.

Per a això, i en particular per poder copsar el segon objectiu, que és l'aportació fonamental d'aquesta recerca, s'està utilitzant una perspectiva d'investigació interdisciplinària i una metodologia mixta (quantitativa i qualitativa): 1) anàlisi documental (monografies, articles de revistes especialitzades, premsa, documents audiovisuals, etc.); 2) explotació de fonts sociodemogràfiques oficials (Movimiento Natural de la Población, Encuesta Nacional de Inmigrantes-ENI 2007 i Censo 2011); 3) explotació de dades pròpies, obtingudes a partir de treball de camp etnogràfic, amb observació participant, grups focals amb fills de parelles mixtes i no mixtes, i entrevistes semidirigides (94) a immigrants en unions mixtes i no mixtes, on també es recull informació sobre xarxes personals (amb el programa Egonet) i capital social (amb un generador de posicions). Amb aquesta combinació de metodologies s'intenta copsar els

3. Inmigración y uniones mixtas: etnicidad e integración social (CSO2011-23242, VI Pla Nacional d'I+D+I 2008-2011 del Ministeri de Ciència i Innovació) i E pluribus unum: immigració, mestissatge i cohesió social (Aposta-UAB 2011). En ambdós casos, l'investigador principal és el Dr. Dan Rodríguez-García, que vol agrair a les institucions finançadores el seu ajut. 
diferents nivells d'anàlisi (micro, a partir de les entrevistes individuals; meso, a partir de l'estudi de xarxes i els grups focals; i macro, a partir de l'anàlisi estadística), i superar alhora la limitació de cada un d'ells per separat. Tanmateix, s'ha intentat integrar al màxim els diferents nivells d'anàlisi utilitzant les mateixes estructures (enfocaments, preguntes i variables) en cada una de les tècniques utilitzades per poder després comparar i analitzar els diferents tipus d'informació conjuntament.

Pel que fa a l'objectiu o nucli teòric de l'estudi, cal assenyalar que la relació entre unions mixtes i integració social és complexa i difícil de mesurar. D'entrada, hi ha diferents maneres d'entendre la integració social. Aquí operacionalitzem "integració» en termes d'inserció o orientació cap a la societat d'acolliment (Catalunya) a diferents nivells (econòmic-laboral, social, cultural, identitari, etc.) (Penninx, 2005). Així, hem tingut en compte si el tipus d'unió (mixta o no mixta) incideix i de quina manera en la inserció legal (adquisició d'estatus legal de resident/ciutadà), la inserció/mobilitat laboral, la socialització i participació social, l'adquisició de capital humà (per exemple, la competència cultural-idiomàtica) i la composició (amplitud i heterogeneïtat) de les xarxes socials, entre d'altres.

Alhora, cal aclarir si la unió mixta causa integració o si, al contrari, és la mateixa integració la que porta a la formació d'unions mixtes. En el cas de les xarxes socials, per exemple, s'ha argumentat en les dues direccions: tant que la integració en xarxes socials porta que hi hagi més unions mixtes (Gordon, 1964), com que és la unió mixta la que porta a més integració en xarxes socials (Scott i Cartledge, 2009). Una forma de contrastar la relació entre aquestes dues variables és mitjançant l'anàlisi retrospectiva, analitzant el moment de formació de la parella, si va ser abans o després de la migració del membre immigrat, ja que la formació de la parella abans de la migració pot portar (causar) la integració, però no es pot tenir seguretat a la inversa. En canvi, si la parella s'ha format després de la migració, la unió pot ser tant la causa com l'efecte de la integració. Això s'ha aplicat tant al guió d'entrevistes semidirigides com al qüestionari de xarxes personals. Així mateix, per mesurar aquesta relació (mixt/integració) cal comparar els casos d'unions mixtes i no mixtes, $i$ assegurar-se que ambdós grups siguin sociodemogràficament comparables.

La mostra amb què s'ha treballat és per quotes, no probabilística. S'han escollit set orígens immigrants (Romania, el Marroc, el Senegal, la República Dominicana, l’Equador, el Pakistan i la Xina), atenent tant al seu volum a Catalunya com a la incidència d'unions mixtes dins el col-lectiu, i s'han agafat tant grups amb una alta incidència d'unions mixtes (per exemple, dominicans), com d'altres on la incidència és molt menor (per exemple, pakistanesos). El nombre d'entrevistes en cada cas s'ha ajustat en funció d'aquestes característiques.

S'ha treballat amb dos tipus d'unions: mixtes o exogàmiques (d'immigrats nascuts a l'estranger amb nadius nascuts a Espanya i residents a Catalunya i de pares també nadius) i no mixtes o endogàmiques (ambdós immigrants del mateix origen). Els immigrants entrevistats han estat aproximadament el $50 \%$ homes i el 50\% dones. La mostra s'ha diversificat també (equiparada 
per mixtos i no mixtos) en funció del lloc de residència (quatre províncies de Catalunya, proporcionalment a la presència del col-lectiu), i intentant incloure l'heterogeneïtat interna de cada col-lectiu i fent que el perfil sociodemogràfic entre mixtos i no mixtos fos semblant en funció de característiques com el lloc de residència, el nivell educatiu i laboral/econòmic, l'edat, la trajectòria migratòria, els anys de residència a Espanya o el subgrup ètniccultural.

A continuació fem alguns comentaris pertinents sobre la metodologia que específicament abordem en aquest article: l'anàlisi de l'ENI i les xarxes personals.

Pel que fa l'anàlisi de dades de fonts estadístiques oficials, cal esmentar primer de tot les grans limitacions per a l'estudi de les unions mixtes a partir de dades secundàries a Espanya, fet que ha estat àmpliament discutit en treballs anteriors sobre la qüestió (Rodríguez-García 2002: 415-42; Cortina, Esteve i Jiménez, 2008; Esteve i Bueno, 2010). Farem aquí només un breu resum de les fonts disponibles en el moment actual. Per treballar dades d'estoc de parelles exogàmiques i endogàmiques a Espanya i a Catalunya disposem d'algunes fonts que ja han quedat allunyades en el temps. Així, el Cens de 2001 no serveix per reflectir la situació actual, a causa de la forta intensitat dels fluxos migratoris que van tenir lloc justament durant la primera meitat del període intercensal (2001-2011) i del grau d'integració d'una població immigrada més assentada al país que va anar en paral.lel a l'augment de la incidència d'unions mixtes. Caldrà esperar les dades sobre habitatge del nou Cens de 2011 per proporcionar una visió més detallada i precisa de la distribució i dels determinants de les relacions endògames-exògames en el present.

Continuant amb dades d'estoc, disposem de la informació de l'Enquesta Nacional d'Immigrants (ENI) de 2007, l'Enquesta de Població Activa (EPA) en les diferents onades, que aporta una visió longitudinal de la qüestió, i, per al cas català, l'Enquesta Demogràfica de 2007. Les dades d'enquesta presenten com a problema principal la dificultat d'explotació i de desagregació per limitacions de representativitat de la mostra, la qual cosa impedeix abordar l'estudi específic de contextos geogràfics més reduïts o de col-lectius determinats. Són aquestes limitacions les que, per al nostre treball, aconsellen l'ús de l'ENI com a font principal per analitzar dades d'estoc.

En referència a les dades de fluxos, les estadístiques del moviment natural de la població (MNP) ofereixen els registres dels matrimonis celebrats dins de les nostres fronteres (fet que representa un biaix, ja que moltes parelles endogàmiques opten per casar-se al país d'origen), i a més no recullen informació sobre altres tipus d'unions consensuals. També es pot fer l'apropament al tema utilitzant els registres sobre naixements, que a partir de 2007 incorporen informació sobre la nacionalitat dels pares (que ja existia en anys anteriors) i sobre el seus països de naixement. Això, però, tampoc no està exempt d'inconvenients, atès que només s'inclouen les parelles que han tingut fills a Espanya en el període estudiat, fet que delimita considerablement l'edat de les persones registrades. No obstant això, és probable que la imatge de l'evolució del fenomen pel que fa a la distribució dels naixements de 
pares en unions mixtes i no mixtes en la població en edat fertil sigui bastant fidel a la realitat estudiada sobre tipus d'unions. Ens quedem, per tant, amb aquesta perspectiva, tenint en compte les restriccions ja comentades: són dades de fluxos, no podem conèixer a través d'elles la panoràmica completa en un moment concret, i els grups d'edats susceptibles de ser incorporats són aquells que poden tenir descendència (lògicament, es restringeix sobretot l'edat de les mares).

Pel que fa a l'anàlisi de xarxes, cal dir que ha demostrat ser una metodologia molt útil en la identificació de processos i estructures d'interacció social (Bott, 1990; Wellman i Berkowitz, 1988, McCarty, 2002; McCarty et al., 2007; Molina et al., 2007), inclòs l'àmbit de les migracions, la integració social i l'etnicitat (Lubbers et al., 2007; Miguel Luken et al., 2007; Brandes et al., 2010). Aquest enfocament permet descobrir el grau en què es formen, mantenen i trenquen relacions, així com la seva importància. Les variacions en aquests aspectes reflecteixen diferents processos d'integració sociocultural. Per tal d'explorar la relació entre unió mixta i integració social, quelcom que pràcticament cap estudi no ha fet fins ara, en aquest projecte s'ha elaborat un qüestionari de xarxes personals i s'ha implementat en el programa Egonet per a la recollida de dades assistides per ordinador i per a la visualització i anàlisi de les xarxes. El qüestionari recull la informació de la xarxa personal de cada enquestat o ego (94 membres de parelles mixtes o exogàmiques i també no mixtes o endogàmiques), sobre els seus vincles personals o alteri (30 en cada cas), les característiques de cadascun d'ells (entre uns i altres, l'origen geogràfic, la durada de la relació, com es van conèixer i la proximitat emocional) i sobre les relacions que existeixen entre ells. Això ens dóna informació sobre la composició i l'estructura (densitat, heterogeneïtat) de les xarxes personals en cada cas, i la temporalitat amb què aquestes relacions s'han format. Així, podrem observar si la presència d'espanyols és més nombrosa en les unions exogàmiques i si les relacions amb espanyols són més fortes o més integradores en les seves xarxes. A més, podrem valorar si en les unions mixtes la persona immigrada coneix una major proporció d'espanyols a través de la parella o si el paper de la parella és més central en les xarxes dels matrimonis mixtos. Entre les variables explicatives o independents considerarem, d'una banda, característiques individuals com el sexe, el grup ètnic de pertinença, el nivell acadèmic $i$ el temps de residència a Espanya, i, d'altra banda, característiques de la xarxa personal, com la presència relativa d'espanyols i la densitat o l'heterogeneïtat d'aquesta, com a variables dependents.

\section{Resultats}

\subsection{Resultats a partir de l'anàlisi de fonts estadístiques: ENI}

a) Col.lectius d'estudi $i$ unions mixtes segons les fonts oficials

Ens apropem aquí a la quantificació de la incidència de les unions mixtes en els nostres col-lectius d'interès a partir de les dades d'estoc de 2007 de l'ENI. Prenem Espanya com a marc territorial de referència per qüestions de repre- 


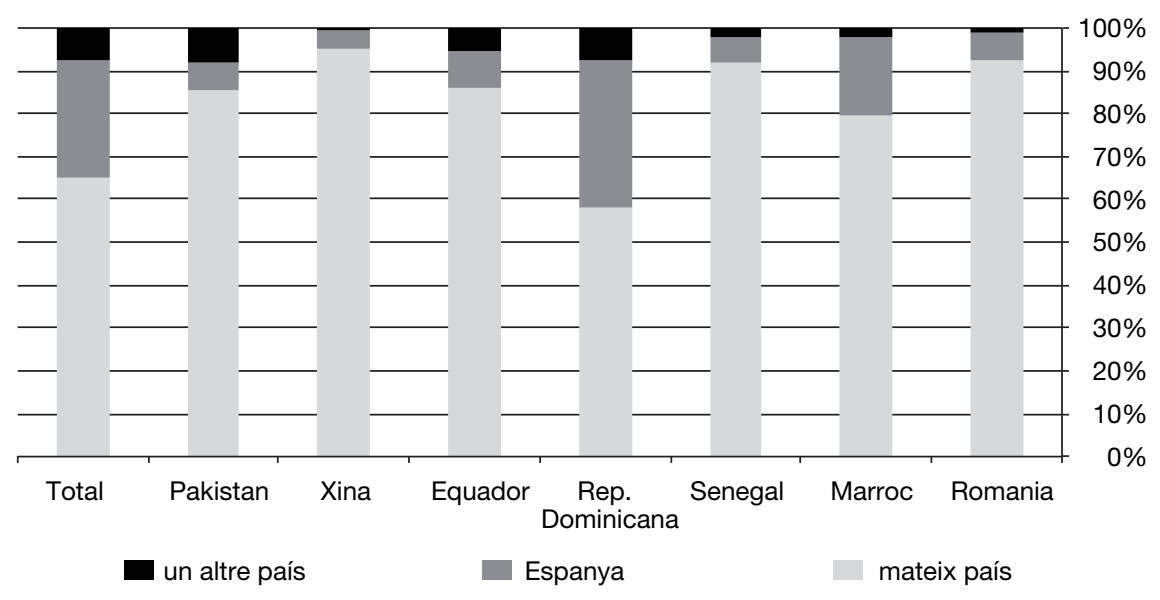

Gràfic 1. Unions segons el país de naixement de la persona enquestada i el lloc de naixement de la parella. Espanya. 2007. Percentatge

Font: elaboració pròpia amb dades de l'ENI 2007.

sentativitat de la mostra ${ }^{4}$. Emprem com a variable fonamental de comparació el país de naixement, que és més adient per als objectius de la recerca (contacte i relació amb país/cultura d'origen, xarxes personals, identitat, integració sociocultural, etc.), i no la nacionalitat, a causa del fenomen de naturalització i el consegüent efecte d'invisibilitat de la primera.

Si comparem les proporcions d'unions endogàmiques del total de la població nascuda a l'estranger i resident a Espanya el 2007 amb les dels nostres col.lectius d'interès (gràfic 1), trobem que únicament el grup de dominicans ${ }^{5}$ $(57,9 \%)$ queda per sota de la xifra per al total $(65,3 \%)$. A l'altre extrem, tres procedències (el Senegal, Romania i la Xina) superen el 90\% d'unions amb persones nascudes al mateix país o endogàmiques.

Com ja s'ha esmentat a la introducció, està força estesa en la literatura acadèmica la interpretació que els nivells més elevats d'exogàmia estan associats amb processos més avançats d'integració, però hi ha múltiples factors que poden incidir en les possibilitats reals a l'hora de trobar parella d'un o altre origen. Aquests factors estan lligats, de forma important, a les probabilitats d'interacció amb la població autòctona, amb la de la mateixa procedència geogràfica (on incideix l'equilibri per sexes intragrups), o amb la de tercers països. Així, el temps de residència a Espanya incentivarà a priori el contacte amb espanyols i augmentarà el domini de les llengües oficials (o, com a mínim, d'alguna d'elles) i potenciarà l'apropament nadiu-immigrant en altres aspectes

4. Es pot consultar una explotació de l'ENI en l'àmbit de Catalunya per a aquest tema a Miguel Luken et al. (2012: 136-139).

5. Quan no s'expliciti el contrari, l'ús del masculí és genèric i inclou ambdós sexes. 


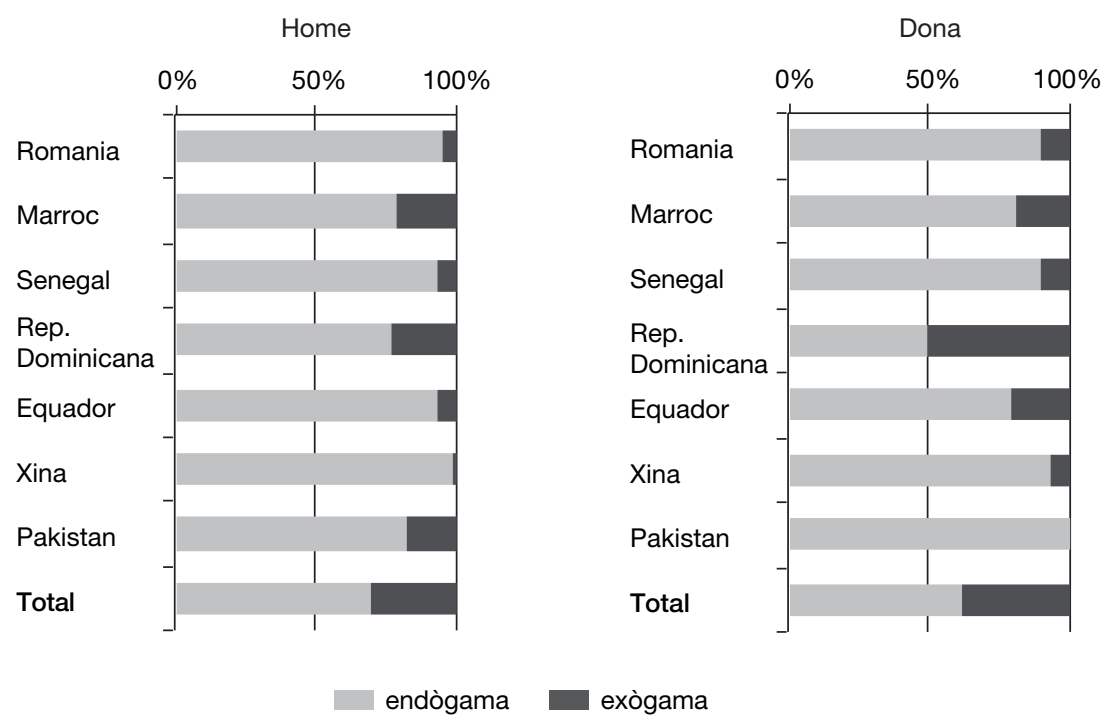

Gràfic 2. Tipus d'unió segons sexe i país de naixement de la persona enquestada. Espanya. 2007. Percentatge

Font: elaboració pròpia amb dades de l'ENI 2007.

culturals. En el cas dels dominicans, per exemple, el coneixement del castellà pot propiciar la comunicació amb persones nascudes a Espanya (tot i que en el cas equatorià aquesta variable no semblaria actuar de la mateixa manera). Per la seva banda, la població marroquina (amb un 18,2\% d'unions amb espanyols) exemplificaria la hipòtesi sobre els temps de residència, ja que es tracta d'una immigració històrica i amb fluxos importants ja des dels anys vuitanta (a diferència d'altres nacionalitats d'immigració molt més recent).

La major similitud en els nivells formatius/educatius o homogàmia social també és un factor que condiciona la probabilitat de formar parella mixta o no mixta; això explica, per exemple, el major nombre d'unions mixtes entre europeus i argentins, que entre andins i europeus, ja que els primers tenen nivells socioeducatius més semblants. Els homes pakistanesos (7,9\%) i els homes i dones dominicans $(7,3 \%)$ són els únics que se situen prop del 7,4\% de la mitjana per a Espanya en unions amb parelles de tercers països.

Les tendències a la unió amb persones d'igual o diferent procedència varien força segons el sexe de la persona immigrada (gràfic 2). En general, veiem que són més exògames les dones $(38,7 \%)$ que els homes $(31,1 \%)$. Romaneses, equatorianes, xineses i senegaleses s'emparellen més amb espanyols que no pas ells amb espanyoles. Però el país que millor reflecteix la diferència és la República Dominicana, en part per la incidència del mercat matrimonial que opera a distància (Miguel Luken et al., 2007). Tot i que proporcionar dades a 
escala macro no necessàriament explica les relacions causa-efecte, a escala micro és presumible l'efecte que els índexs de masculinitat tenen sobre la distribució de tipus d'unions per sexe (i que conseqüentment també afecta l'estructura d'oportunitats). En el cas de la República Dominicana, trobem 58 homes per cada 100 dones $\mathrm{i}$, en el cas pakistanès, 725 homes per cada 100 dones (dades del Padró Continu de 2007).

A més d'aquests desequilibris, els factors culturals-religiosos estarien darrere la diferència observada entre els pakistanesos, com suggereixen algunes entrevistes en profunditat fetes en el nostre treball de camp: elles no es casen amb homes d'altres procedències, no es concep la possibilitat ni entre dones que es consideren integrades en la societat catalana; però, en canvi, ells actuen amb una "flexibilitat» que supera la dels homes equatorians, senegalesos, xinesos $\mathrm{i}$ romanesos.

L'estructura per edat i la situació de convivència afegeixen altres elements interpretatius. Els senegalesos tenen uns dels índexs de masculinitat més elevats (536 homes per cada 100 dones) però, malgrat això, la proporció d'unions exogàmiques és lleugerament superior entre elles, la qual cosa podria explicar-se en part perquè molts d'ells són solters sense emparellar $\mathrm{i}$, per tant, no apareixen en aquestes xifres. En tot cas, les interaccions són variades i s'han d'estudiar amb un volum de dades considerable si es volen establir diferències significatives entre orígens (Cortina, Esteve i Jiménez 2008).

\section{b) L'efecte del tipus d'unió en alguns indicadors d'integració}

Per tal de relacionar l'efecte del tipus d'unió amb la integració de la persona immigrada, hem creat alguns indicadors relacionats amb quatre eixos essencials en el procés d'inserció de la persona immigrada en la societat receptora: treball, habitatge, llengua i participació social (taula 1 ).

És important aquí escollir indicadors que mesurin la situació en relació amb el nivell d'integració en el moment de l'entrevista, moment de referència del tipus de relació en parella, perquè d'aquesta manera podrem garantir, en general, que l'inici d'aquesta relació és anterior a la posició que estableix l'indicador per a cada persona. La qüestió laboral s'ha valorat tenint en compte l'últim estatus ocupacional al país d'origen i l'últim declarat a Espanya (sobre la darrera setmana abans de l'entrevista). Amb la comparació d'aquestes dues referències establim una variable de mobilitat laboral amb tres categories: descendent, no-mobilitat i ascendent. S'aplica un model multinomial per relacionar aquestes tres categories i estudiar l'efecte de les nostres variables explicatives i de control.

D'altra banda, la qualitat de l'habitatge es mesura amb un índex creat segons el nombre d'habitacions per persona i una variable de recompte de problemes associats a l'habitatge i l'entorn. Per crear aquesta última variable s'han tingut només en compte els aspectes més simptomàtics de problemes reals amb l'habitatge (manca d'aigua corrent, manca d'electricitat, etc., fins a un total de deu factors). L'índex final es crea com a producte d'aquest últim indicador (en sentit invers, quantitats més baixes corresponen a llars amb més 
mancances) i el nombre d'habitacions per persona a l'habitatge. El model aplicat és un model de regressió lineal estàndard, atès el caràcter continu de la variable quantitativa resultant.

Com a nivell de castellà o llengua cooficial s'ha pres el nivell més alt de totes dues llengües, tenint en compte els valors registrats per a les diferents habilitats (comprendre, parlar, llegir i escriure). Pel tipus de variable resultant també s'ha optat per una regressió lineal múltiple.

Per acabar, atesos els baixos nivells generals de participació en associacions, siguin aquestes específiques per a població immigrada o no, s'ha construït una variable dicotòmica (sí/no) que s'ha incorporat com a variable dependent en un model de regressió logística.

Per poder establir veritables relacions causa-efecte caldria disposar d'informació més detallada sobre el moment de realització de cada esdeveniment o experiència. No obstant això, incorporem la variable de data de matrimoni, considerant si ha estat abans o després de l'emigració de la persona entrevistada, $i$ tenim en compte fenòmens mesurats en el moment de l'entrevista per poder establir en certa manera un ordre cronològic.

\section{Treball}

Quan es compara la probabilitat d'haver millorat la posició ocupacional amb la de mantenir-la igual, o que aquesta hagi empitjorat en lloc que hagi quedat més o menys estable, l'efecte de trobar-se en unió mixta no aporta cap clau de comprensió del fenomen, que sembla seguir un procés més complex en què, no obstant, l'origen sí que té un pes explicatiu important. L'únic resultat destacable pel que fa a la influència del tipus de matrimoni és que el fet que sigui unió endogàmica incrementa la probabilitat d'una mobilitat laboral descendent, la qual cosa denota un efecte negatiu d'aquest tipus d'unió sobre la qüestió laboral. No obstant això, cal matisar aquesta conclusió, ja que si el matrimoni s'ha produït després de la immigració, aquest efecte es veu atenuat, probablement com a resposta al fet que la gent tendeix a casar-se i formar família quan les condicions econòmiques ho permeten, $\mathrm{i}$ una mobilitat descendent probablement no indicaria aquesta situació d'estabilitat i seguretat laboral. En canvi, els valors positius del coeficient per a "casat després de la immigració» en tots dos models relacionats amb el treball (mobilitat ascendent comparada amb no-mobilitat i mobilitat descendent comparada amb no-mobilitat) no assenyala una direcció clara en l'efecte d'aquesta variable quan el matrimoni és mixt (amb nascuts a Espanya). 
Taula 1. Models de regressió per als diferents indicadors sobre integració

\begin{tabular}{|c|c|c|c|c|c|c|}
\hline & & \multirow{2}{*}{\multicolumn{2}{|c|}{ Mobilitat laboral }} & \multicolumn{3}{|c|}{$\begin{array}{l}\text { Nivell de } \\
\text { castellà } 0 \\
\text { d'una altra }\end{array}$} \\
\hline & & & & \multirow{2}{*}{$\begin{array}{l}\text { Qualitat de } \\
\text { l'habitatge }\end{array}$} & \multirow{2}{*}{$\begin{array}{l}\text { llengua } \\
\text { cooficial }\end{array}$} & \multirow{2}{*}{$\begin{array}{c}\text { Participació } \\
\text { social }\end{array}$} \\
\hline & & Ascendent I & Descendent & & & \\
\hline \multicolumn{2}{|l|}{ Anys de residència a Espanya } & $0,027^{\star \star}$ & $-0,015$ & $0,052^{\star \star}$ & $0,024^{\star \star}$ & $0,006^{*}$ \\
\hline \multirow[t]{13}{*}{ Lloc de naixement } & Europa 15 i CEE & Ref. & Ref. & Ref. & Ref. & Ref. \\
\hline & Romania & $-0,604^{\star *}$ & $0,819^{\star \star}$ & $-2,930^{\star \star}$ & $1,089^{\star \star}$ & $-0,938^{\star *}$ \\
\hline & Resta d'Europa & $-0,608^{\star}$ & $1,100^{\star \star}$ & $-2,545^{\star \star}$ & $0,851^{\star \star}$ & $-1,118^{\star *}$ \\
\hline & Rep. Dominicana & $-0,812$ & $0,866^{\star \star}$ & $-3,288^{\star \star}$ & & $-0,357$ \\
\hline & Equador & $-0,609^{\star}$ & $0,948^{\star \star}$ & $-3,747^{\star \star}$ & & $-0,862^{\star \star}$ \\
\hline & Resta de Llatinoamèrica & $-0,530^{\star \star}$ & $0,971^{\star \star}$ & $-2,780^{\star \star}$ & & $-0,299^{\star \star}$ \\
\hline & Marroc & 0,346 & $1,408^{\star \star}$ & $-3,103^{\star \star}$ & $0,578^{\star \star}$ & $-0,645^{\star \star}$ \\
\hline & Senegal & $-0,421$ & $1,982^{\star \star}$ & $-4,198^{\star \star}$ & 0,223 & $1,347^{\star \star}$ \\
\hline & Resta d'Àfrica & $-0,557$ & $1,681^{\star *}$ & $-2,533^{\star \star}$ & $0,730^{\star \star}$ & $-0,100$ \\
\hline & Xina & 0,934 & $-0,165$ & $-3,908^{\star \star}$ & $0,584^{\star \star}$ & $-1,910^{\star \star}$ \\
\hline & Pakistan & $1,417^{\star}$ & $2,352^{\star \star}$ & $-3,950^{\star \star}$ & $0,667^{\star \star}$ & 0,363 \\
\hline & Resta d'Àsia† & 0,829 & $1,503^{\star \star}$ & $-3,270^{\star \star}$ & 0,219 & $-0,266$ \\
\hline & Oceania†† & 0,462 & 0,650 & $-2,081^{\star \star}$ & $-0,034$ & 0,064 \\
\hline \multirow{2}{*}{$\begin{array}{l}\text { Moment del matrimoni en } \\
\text { relació amb el d'immigració }\end{array}$} & Abans 0 en el mateix any & Ref. & Ref. & Ref. & Ref. & Ref. \\
\hline & Després & $0,621^{\star \star}$ & $0,486^{\star \star}$ & $-1,850^{\star \star}$ & 0,001 & 0,122 \\
\hline \multirow{3}{*}{$\begin{array}{l}\text { Lloc de naixement } \\
\text { de la parella }\end{array}$} & Espanya & Ref. & Ref. & Ref. & Ref. & Ref. \\
\hline & País de l'ego & 0,355 & $0,986^{\star \star}$ & $-1,204^{\star \star}$ & $-0,855^{\star \star}$ & 0,099 \\
\hline & Un altre país & 0,203 & 0,584 & $-0,291$ & $-0,389^{\star \star}$ & $0,555^{\star \star}$ \\
\hline \multirow{2}{*}{$\begin{array}{l}\text { Moment del matrimoni* } \\
\text { lloc de naixement }\end{array}$} & Després*País de l'ego & $-0,667^{\star}$ & $-0,828^{\star \star}$ & $1,472^{\star \star}$ & $0,672^{\star \star}$ & $-0,116$ \\
\hline & Després*Un altre país & $-0,187$ & $-0,886$ & 0,358 & 0,051 & $-0,748^{\star \star}$ \\
\hline \multirow[t]{3}{*}{ Nivell d'estudis } & Primària o menys & Ref. & Ref. & Ref. & Ref. & Ref. \\
\hline & Secundària & 0,140 & $0,447^{\star \star}$ & $0,781^{\star \star}$ & $0,642^{\star \star}$ & $0,315^{\star \star}$ \\
\hline & Superior & $-0,291$ & $0,429^{\star \star}$ & $1,278^{\star \star}$ & $0,869^{\star \star}$ & $0,734^{\star \star}$ \\
\hline \multirow[t]{2}{*}{ Sexe } & Home & Ref. & Ref. & Ref. & Ref. & Ref. \\
\hline & Dona & $0,355^{\star \star}$ & $0,895^{\star \star}$ & $-0,186$ & $-0,020$ & $-0,070$ \\
\hline Constant & & $-1,713^{\star \star}$ & $-2,591^{\star \star}$ & $11,205^{\star \star}$ & $3,455^{\star \star}$ & $-1,473^{\star \star}$ \\
\hline $\begin{array}{l}\text { † (sense el Japó i Corea d } \\
+† \text { i resta de països deser } \\
{ }^{*} p<0,1 \\
{ }^{* \star} p<0,05\end{array}$ & $\begin{array}{l}\text { lel Sud) } \\
\text { nvolupats }\end{array}$ & & & & & \\
\hline
\end{tabular}

Nota. Per a totes les variables els models s'han fet amb el programa Stata amb les dades ponderades.

Font: elaboració pròpia a partir de l'ENI 2007.

En tot cas, no hem d'oblidar que la mobilitat es mesura en termes relatius. És a dir, una mobilitat ascendent serà més difícil si ja es parteix d'una situació avantatjada, la qual cosa explicaria els valors positius corresponents a educació secundària $\mathrm{i}$ superior en relació $\mathrm{amb}$ la primària o menys per a la mobilitat descendent. Aquest mateix argument podria ajudar a interpretar els estimadors per als països. Així, es veu clar que la majoria de procedències tenen una pro- 
babilitat més elevada de mobilitat descendent que la dels països de l'Europa 15 i CEE. En canvi, el nombre d'estimadors significatius decreix quan fixem l'atenció en la mobilitat ascendent, per a la qual els països de l'est d'Europa i la majoria de llatinoamericans es veuen amb els coeficients negatius significatius. Potser la posició inicial de les persones vingudes d'aquests països, amb un capital humà generalment més elevat que el de moltes persones vingudes d'Âfrica, fa que la seva mobilitat ascendent (en les circumstàncies de mercat laboral desigual) sigui més complicada.

\section{Habitatge}

En la qualitat de l'habitatge sí que s'aprecien diferències significatives a favor de les unions mixtes. A més, hi ha un efecte remarcable i diferencial del moment del matrimoni en relació amb el de la immigració. Si els matrimonis mixtos amb espanyol/a que s'han produït després de la immigració puntuen negativament pel que fa a la qualitat de l'habitatge (probablement indiquen que la posició socioeconòmica de la parella nascuda a Espanya no és en general elevada), aquest efecte s'anul-la quan el matrimoni és anterior o es produeix el mateix any de la immigració (suggereix que les circumstàncies en què s'originen aquestes relacions són molt diferents i, en tot cas, més favorables en qüestió econòmica). La tendència, no obstant això, no és la mateixa quan ens centrem en els matrimonis endogàmics. Aquí, el matrimoni postimmigració tindrà lloc en general quan les condicions siguin prou estables per poder formar una família (sovint comporta la immigració del cònjuge del país d'origen). L'efecte de casar-se després aniria a favor d'una millor qualitat de l'habitatge en comparació amb les persones que immigren ja casades amb parella del mateix país de naixement.

Si en general el temps de residència a Espanya i el nivell d'estudis tenen un efecte positiu sobre els indicadors d'integració contrastats, la diferenciació per orígens continua tenint un pes significatiu després d'haver controlat aquestes variables anteriors. Existeixen diferències, per tant, que semblen estar explicades per barreres ètniques o per situacions de discriminació a la societat receptora. En l'habitatge, el col-lectiu senegalès és el que sobresurt per la seva posició més negativa en el rànquing de països.

\section{Llengua}

L'efecte de la unió mixta apunta en el sentit esperat quan ens referim al domini de les llengües oficials del lloc de residència, que és una forma important d'adquisició de capital humà i també social. Els còmputs finals segons el lloc de naixement del cònjuge estableixen estimadors negatius per a aquelles persones casades amb una altra del mateix país o d'un tercer país, independentment del moment d'arribada. El fet de tenir parella autòctona incideix de forma positiva sobre l'aprenentatge de la/les llengua/es, un cop controlat pel sexe, nivell d'estudis, anys de residència a Espanya i regió o país de naixement. L'efecte de casar-se després de l'emigració, quan es tracta d'un matrimoni endogàmic, atenua, però, l'efecte negatiu d'aquest tipus d'unió sobre el coneixement de 
la llengua. És possible que aquest resultat estigui lligat al fet que es passa més temps fora de la llar/habitatge en un primer temps a Espanya (quan encara no s'ha format família a la destinació) o al fet que les relacions socials estiguin menys vinculades a la família del mateix origen i més als amics (com a resposta, també, a l'etapa del cicle de vida), $i$ això redundi en la necessitat d'un major ús de la/les llengua/es nativa/es.

La resta de variables apunta en el sentit esperat, tot i que és interessant ressaltar que és l'únic model on tots els coeficients significatius segons procedència són positius, en contrast amb la categoria base d'europeus provinents de països rics, la qual cosa indica una integració lingüística més satisfactòria en persones associades inicialment a la immigració de caràcter més econòmic. Especialment destacable és el cas de la població romanesa, a la qual ajuda l'arrel llatina de la seva llengua d'origen. Tanmateix, la diferència entre tenir parella autòctona o no és més pronunciada en el cas dels xinesos (resultats no incorporats). El treball de Miguel Luken et al. (2012: 43-46), amb les dades de l'ENI per a Catalunya, mostra que aquest efecte d'unió amb autòcton és més acusat en el coneixement del català que en el del castellà, i suggereix que l'aprenentatge del català es veu més afavorit per la presència de parelles exogàmiques (en aquest cas, probablement amb català/na) que el castellà.

\section{Participació social}

Atenent a la participació social, estudiada a través de la pertinença a associacions o grups socials, siguin específicament orientats a immigrants o no (i que no arriba al 20\%, segons dades de l'ENI, quan s'agrupen tots els tipus d'associacions), no s'estableix un efecte clar de la presència d'un cònjuge nascut a Espanya a la parella. Els matrimonis mixtos entre immigrants de diferents països de naixement són els que amb més probabilitat pertanyen a algun tipus d'associació, sobretot si s'han casat abans de la immigració. De fet, a partir de les entrevistes hem vist que una via de coneixement i d'inici de la relació per a les parelles mixtes és justament la participació d'ambdues persones en associacions o ONG a l'estranger. Entre unions endògames i exògames amb espanyol/a no es troben diferències destacables. Pel que fa als països de naixement, el Senegal és la procedència que mostra una tendència d'associacionisme més elevada, quan es compara amb els europeus de l'Europa dels 15 i CEE, inclinació que també hem pogut observar amb l'anàlisi qualitativa de les nostres pròpies dades.

\subsection{Primers resultats a partir de l'anàlisi de xarxes personals ${ }^{6}$}

A continuació, presentarem dos casos, un d'una unió mixta i un altre d'una unió endogàmica, per il.lustrar el mètode i fer una descripció (encara no interpretació ni explicació) dels casos.

6. La recol-lecció de dades ha estat portada a terme per les antropòlogues Irina Casado Aijón i Adriana Jarrín Morán, investigadores contractades dins el projecte, a qui volem agrair la seva bona feina. 
Cas 1 (exògam). Xarxa d'una dona nascuda a la República Dominicana casada amb un home nascut a Espanya

En aquest primer cas es tracta d'una dona que ha passat gran part de la seva vida a Espanya. Va arribar quan tenia 18 anys i en l'actualitat en té 42 . Hi ha una certa dissociació entre els estudis realitzats, secundaris, i el seu treball en els serveis de neteja amb un nivell d'ingressos baix. Va conèixer la seva parella actual quan tenia 34 anys i ja feia setze anys que era a Espanya. Anteriorment havia estat casada amb un altre home espanyol, del qual té un fill de 21 anys. Hi ha correspondència entre els nivells educatius i socioprofessionals dels dos cònjuges, encara que en aquest cas tots dos pertanyen a la classe baixa.

La seva xarxa és molt compacta, ja que pràcticament tots es coneixen amb tots i mantenen relacions. Hi ha una àmplia presència de familiars propis (tretze), tan sols un familiar de la parella i força amics (quinze), com es pot observar a les figures $1 \mathrm{i} 2$. La figura 1 mostra la xarxa de l'enquestat, en què l'enquestada mateixa no hi és inclosa. Els trenta nodes representen els trenta alteri i els lligams entre ells representen les relacions que l'enquestat considera que hi ha entre ells (blau fosc indica que hi ha relació, blau clar indica que és possible que n'hi hagi). A la figura 1, els colors representen els diferents rols dels alteri; les formes, el país de residència; i la grandària, la proximitat emocional que l'enquestat sent cap a cada un dels alteri.

A la figura 1 podem veure que casi tots els alteri viuen a Espanya, excepte un familiar, dos amics que viuen a la República Dominicana $\mathrm{i}$ dos amics que viuen en un tercer país (un a l'Europa occidental i un altre a Nord-amèrica). Com es pot observar a la figura 2, tots els familiars de l'ego són d'origen dominicà excepte dos familiars (nascuts a Espanya). És possible observar una majoria clara d'amics d'origen dominicà a la xarxa (deu), només tres espanyols i dos d'altres països (un llatinoamericà i una europea occidental).

La parella apareix al centre de l'entramat social de l'ego i es relaciona amb pràcticament tots els alteri. Té una posició molt pròxima amb els familiars de l'ego. Podríem trobar-nos davant d'un cas del que hem conceptualitzat com a «integració a la inversa», ja que la seva parella espanyola té tendència a integrar-se socioculturalment al món dominicà. L'entrevista qualitativa que acompanya aquest cas ho corrobora.

Finalment, podem dir que la relació amb la seva parella ha tingut una incidència bastant neutra en la seva xarxa actual, ja que ha sofert poques modificacions després d'establir la relació (figura 3), i només ha incorporat un amic a la xarxa de l'ego (figura 4). 


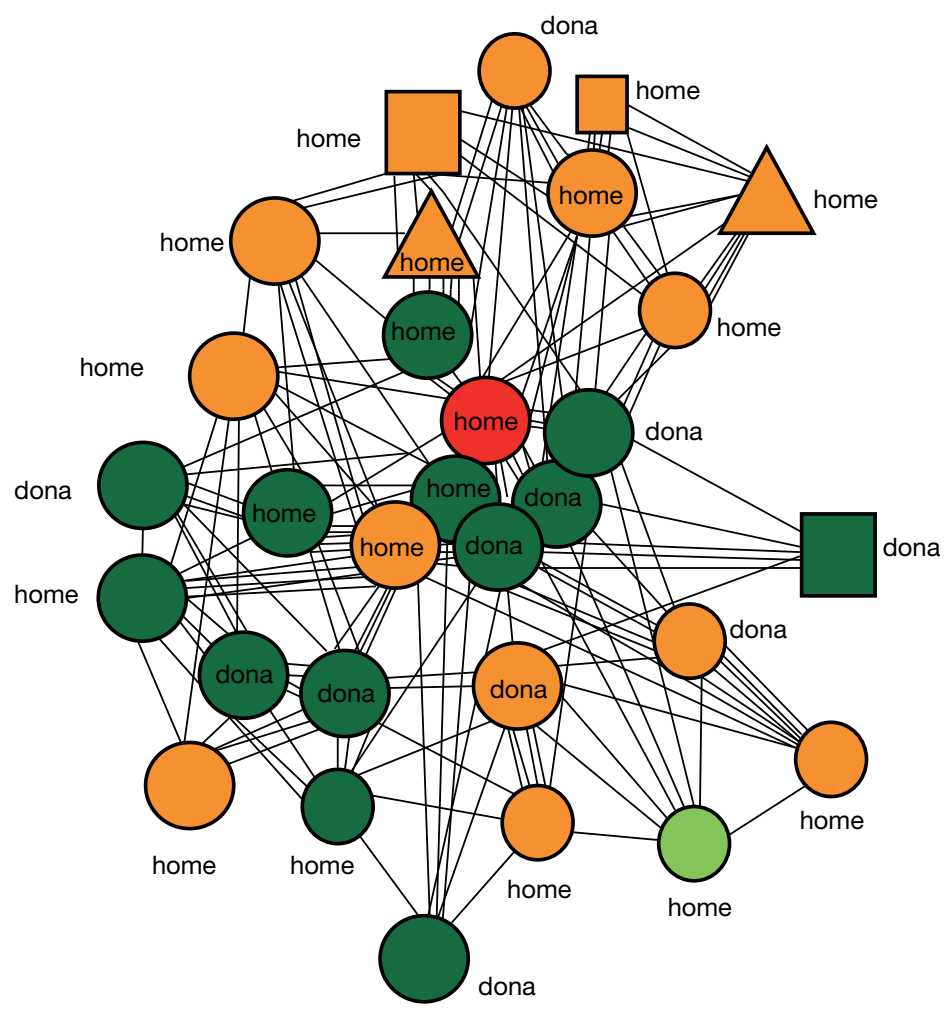

Tipus de relació amb l'ego

Parella

Família de l'enquestat

Família de la parella

Amic/ga

Veí/ina

Company de feina

Un altre
País de residència

Espanya

República Dominicana

Un altre país

Figura 1. Xarxa de dona dominicana exògama (cas 1). Tipus de relació i país de residència dels membres.

Nota per a la lectura de la llegenda: sexe (etiqueta), país de residència (forma), tipus de relació (color) i proximitat emocional (grandària).

Font: elaboració pròpia. 


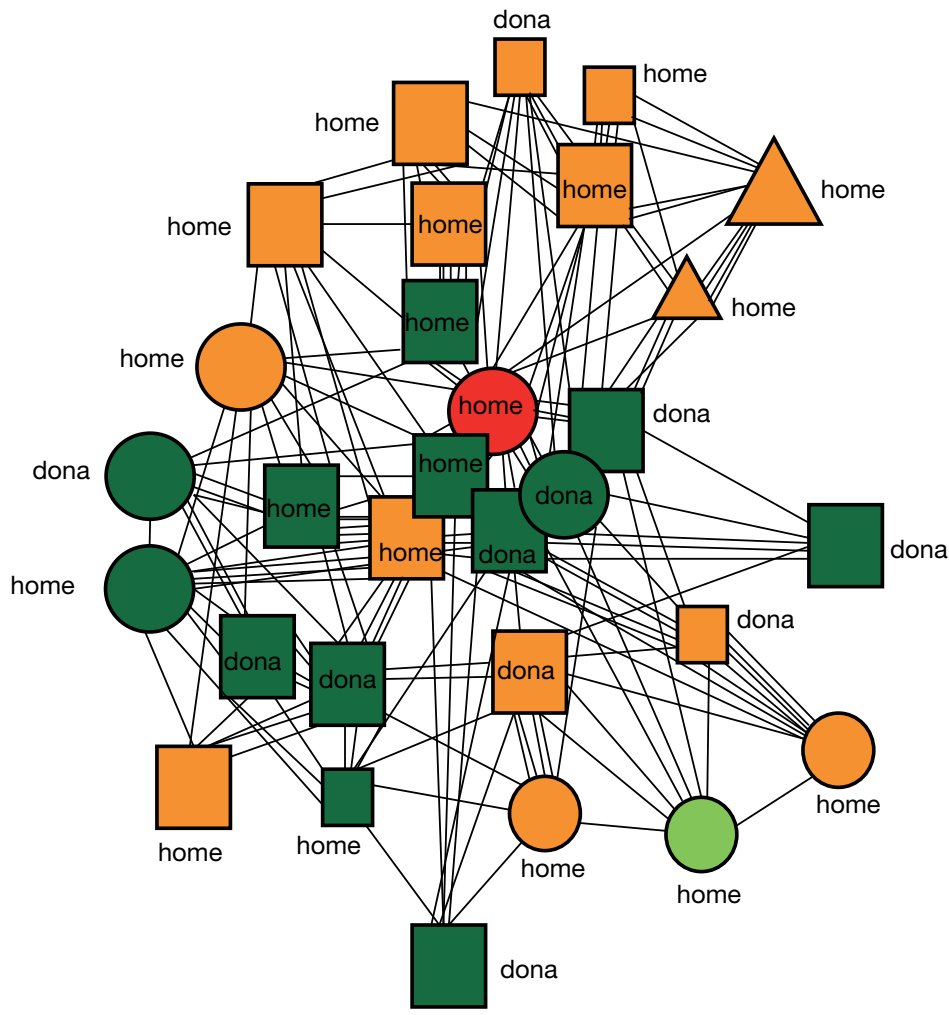

Tipus de relació amb l'ego

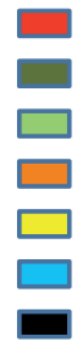

Parella

Família de l'enquestat

Família de la parella

Amic/ga

Veí/ina

Company de feina

Un altre
País d'origen (naixement)

Espanya

República Dominicana

Un altre país

Figura 2. Xarxa de dona dominicana exògama (cas 1). Tipus de relació i país d'origen dels membres.

Nota per a la lectura de la llegenda: sexe (etiqueta), país d'origen/naixement (forma), tipus de relació (color) i proximitat emocional (grandària).

Font: elaboració pròpia. 


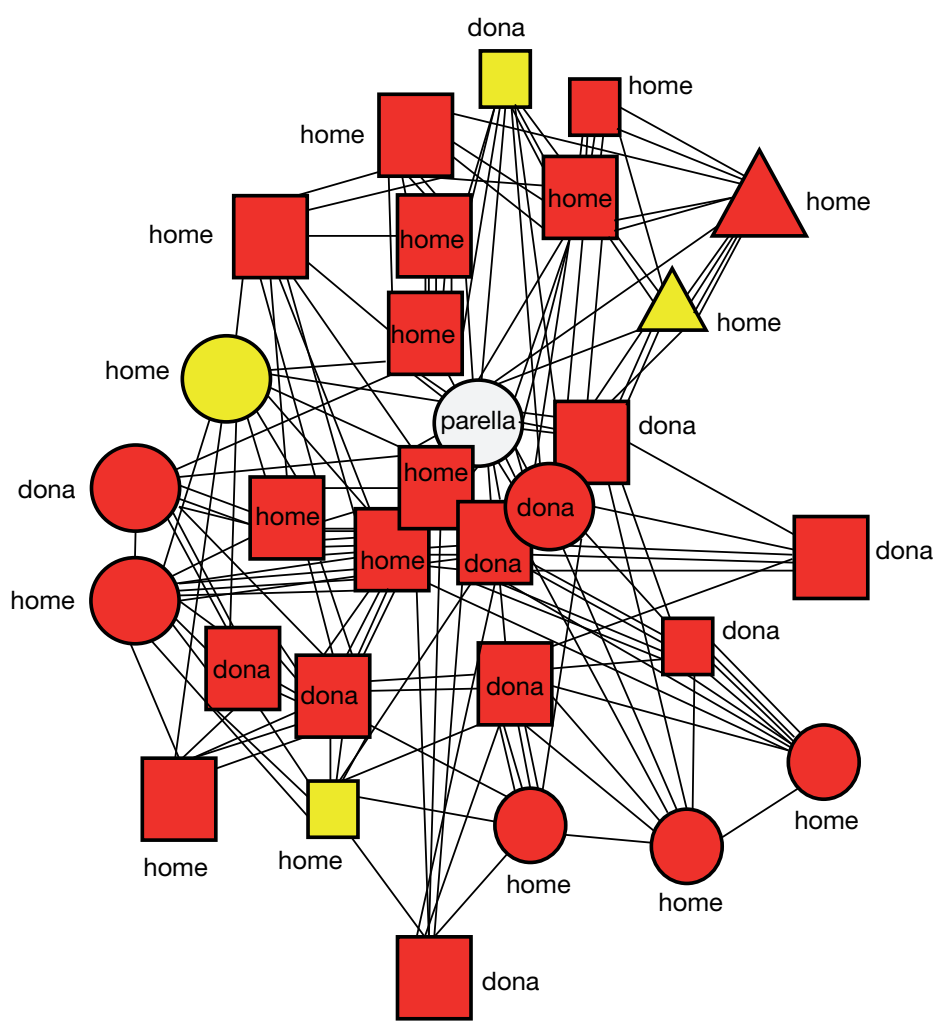

Temporalitat de la relació

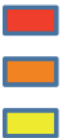

Abans de conèixer la parella

A la vegada que la parella

Després de conèixer la parella
País d'origen (naixement)

Espanya

República Dominicana

Un altre país

Figura 3. Xarxa de dona dominicana exògama (cas 1). Temporalitat de la relació respecte a la de parella i país d'origen dels membres.

Nota per a la lectura de la llegenda: (etiqueta), país d'origen/naixement (forma), proximitat emocional (grandària) i durada de la relació (color).

Font: elaboració pròpia. 


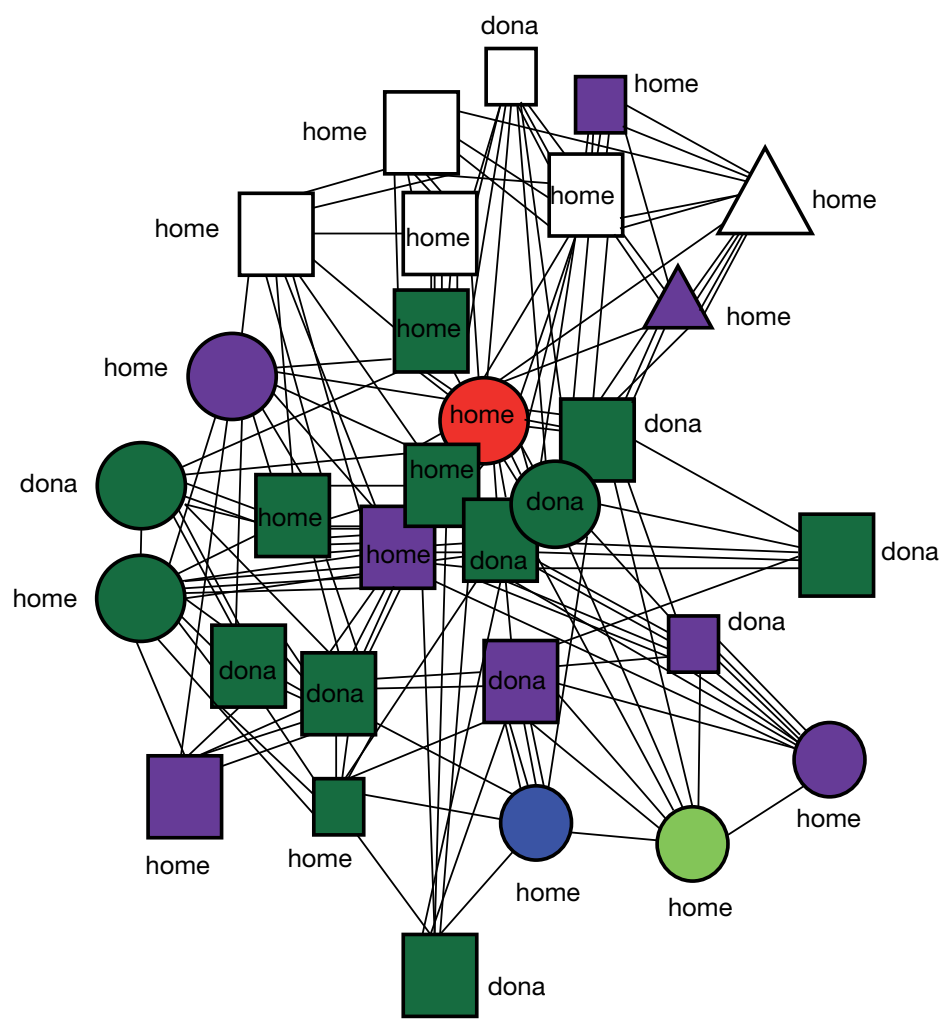

Tipus de relació amb l'ego

País d'origen (naixement)

Amic conegut a través de la seva parella o família

Amic conegut a través d'una altra persona

Amic conegut al col-legi, estudis, a la feina o al barri

Espanya

Amic conegut d'una altra manera

Parella

República Dominicana

Família de l'enquestat

Família de la parella

Veí/ina

Company de feina

Un altre

Figura 4. Xarxa de dona dominicana exògama (cas 1). Via d'establiment de la relació i país d'origen dels membres.

Nota per a la lectura de la llegenda: sexe (etiqueta), país d'origen/naixement (forma), tipus de relació (color) i proximitat emocional (grandària).

Font: elaboració pròpia. 
Cas 2 (endògam). Xarxa d’una dona nascuda a la República Dominicana casada amb un home nascut també a la República Dominicana

Com en el cas anterior, es tracta d'una dona dominicana amb un període de permanència llarg a Espanya, país al qual va arribar fa disset anys (ara en té 51). Amb estudis secundaris, també treballa en el sector de la neteja, encara que en el moment de fer l'entrevista estava a l'atur. Va conèixer fa vint anys la seva parella actual. No té fills amb ella però sí dos d'una relació anterior.

Com podem veure a les diverses figures, ens trobem aquí amb una xarxa social formada per un grup compacte de familiars propis (vint) i amics (nou), amb relacions creuades entre ells i en la qual no hi ha cap familiar de la parella. Tots els amics viuen a Espanya, com també una gran part dels familiars (deu); set viuen a la República Dominicana i tres viuen a l'Amèrica del Nord (figura 5). La parella ocupa una posició central i manté relació amb pràcticament tots

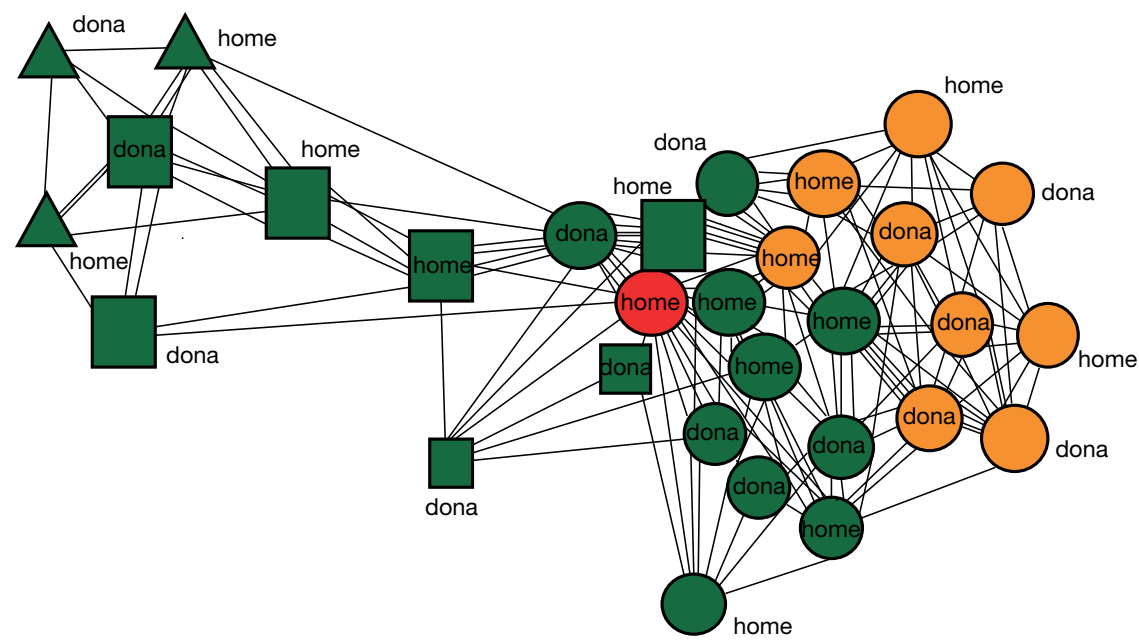

Tipus de relació amb l'ego

Parella
Família de l'enquestat
$\square$ Família de la parella
$\square$ Amic/ga
$\square$ Veí/ina
$\square$ Company de feina
Un altre

País de residència

Espanya

República Dominicana

Un altre país

Figura 5. Xarxa de dona dominicana endògama (cas 2). Tipus de relació i país de residència dels membres.

Nota per a la lectura de la llegenda: sexe (etiqueta), país de residència (forma), tipus de relació (color) i proximitat emocional (grandària).

Font: elaboració pròpia. 


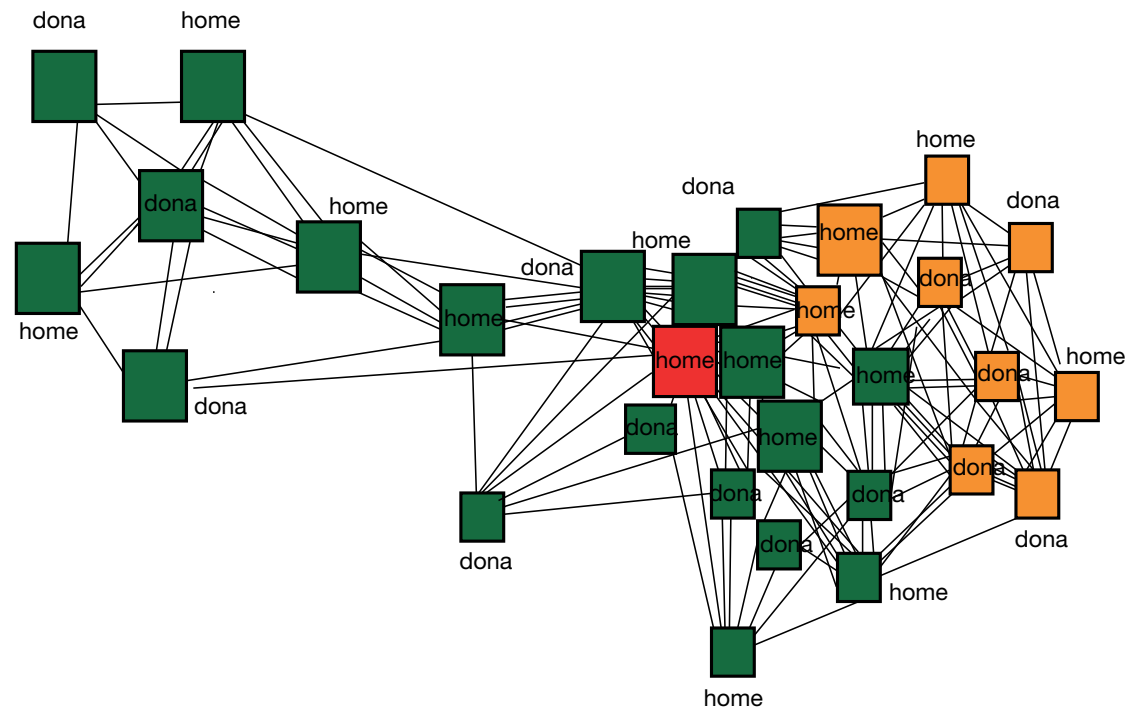

Tipus de relació amb l'ego

País d'origen (naixement)

Parella

Família de l'enquestat

Família de la parella

Amic/ga

Veí/ina

Company de feina

Un altre

Figura 6. Xarxa de dona dominicana endògama (cas 2). Tipus de relació i país d'origen dels membres.

Nota per a la lectura de la llegenda: sexe (etiqueta), país d'origen/naixement (forma), tipus de relació (color) i proximitat emocional (grandària).

Font: elaboració pròpia. 


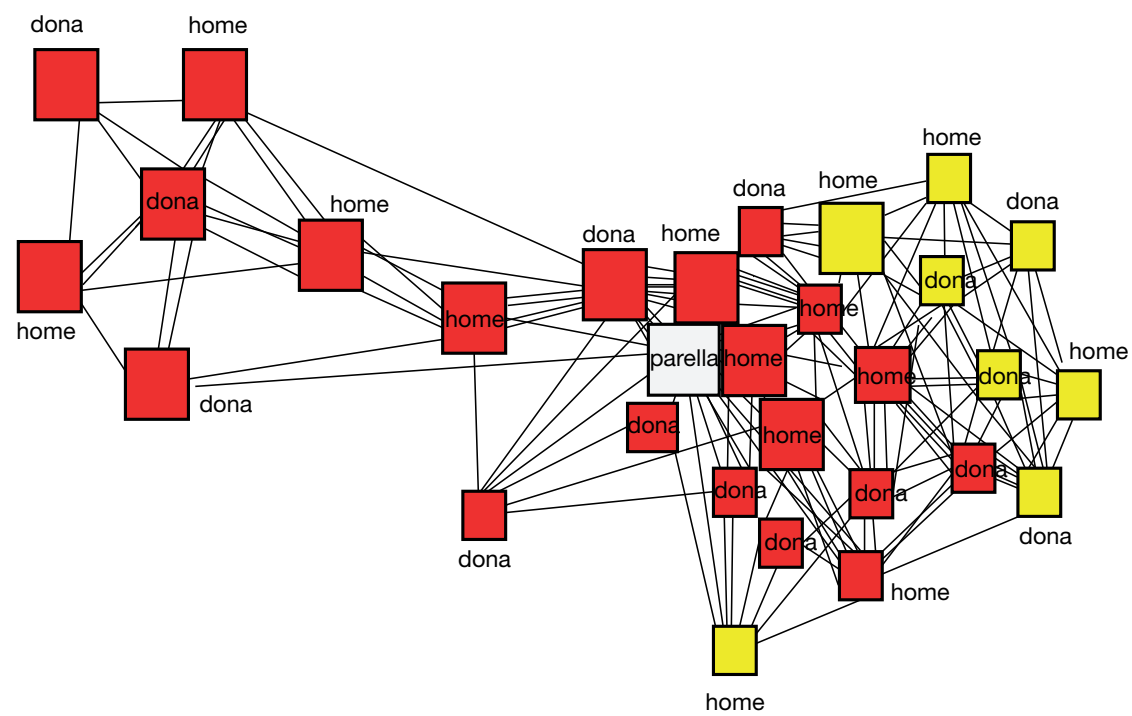

Temporalitat de la relació

Abans de conèixer la parella

$\square$ A la vegada que la parella

$\square$ Després de conèixer la parella
País d'origen (naixement)

Espanya

República Dominicana

Un altre país

Figura 7. Xarxa de dona dominicana endògama (cas 2). Temporalitat de la relació respecte a la de parella i país d'origen dels membres.

Nota per a la lectura de la llegenda: sexe (etiqueta), país d'origen/naixement (forma), proximitat emocional (grandària) i durada de la relació (color).

Font: elaboració pròpia. 


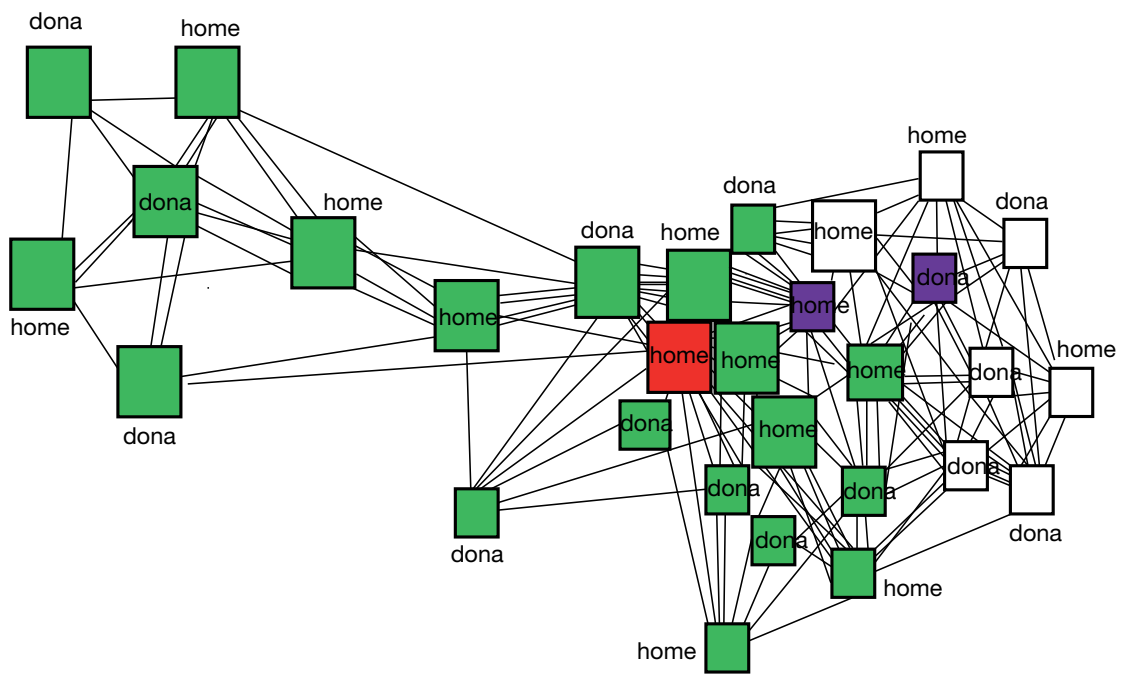

Tipus de relació amb l'ego

- Amic conegut a través de la seva parella o família

Amic conegut a través d'altra persona

$\square$ Amic conegut al col.legi, estudis, a la feina o al barri

Amic conegut d'altra manera

Parella

Família de l'enquestat

$\square$ Família de la parella

$\square$ Veí/ina

Company de feina

Un altre
País d'origen (naixement)

Espanya

República Dominicana

$\triangle$ Un altre país

Figura 8. Xarxa de dona dominicana endògama (cas 2). Via d'establiment de la relació i país d'origen dels membres.

Nota per a la lectura de la llegenda: sexe (etiqueta), país d'origen/naixement (forma), tipus de relació (color) i proximitat emocional (grandària).

Font: elaboració pròpia. 
els amics i familiars de l'ego. Tot i que l'ego ja fa disset anys que és a Espanya, tota la seva xarxa social es compon per alteri d'origen dominicà, com es pot veure a la figura 6 , i la major part d'aquests són anteriors a la formació de la parella (figura 7). No hi ha cap amic/amiga que procedeixi de la relació que manté amb la seva parella actual (figura 8).

\section{Conclusions}

Hem presentat els avenços d'una recerca en curs on s'està intentant clarificar una de les qüestions que ha ocupat els científics socials durant segles: la relació entre les unions/famílies mixtes i la integració sociocultural. Hem vist que, malgrat l'augment demogràfic d'aquest tipus d'unions a Espanya i dels estudis existents respecte d'això, encara hi ha molt poca informació empírica i en profunditat sobre aquesta qüestió, d'altra banda tan complexa de mesurar.

Concretament, s'està aplicant una metodologia mixta per explorar la relació entre unions mixtes (formades per persones de nacionalitat espanyola i persones de nacionalitat estrangera, o entre persones nascudes a l'estranger i persones nascudes a Espanya) i integració dels immigrants a diferents nivells (social, cultural, econòmic i polític), a partir de l'anàlisi d'unions mixtes i no mixtes de set col-lectius immigrats residents a Catalunya: Romania, el Marroc, el Senegal, la República Dominicana, l'Equador, el Pakistan i la Xina.

A partir de les primeres anàlisis de l'ENI, hem pogut veure que hi ha col.lectius més endògams (e.g., Romania, la Xina, el Pakistan) i d'altres més exògams (e.g., la República Dominicana), i que aquestes diferències poden estar condicionades per factors com ara l'equilibri per sexes dins el grup, el temps de residència a Espanya, el projecte migratori o el nivell socioeducatiu. D'altra banda, observem diferències segons el sexe: les dones $(38,7 \%)$ són més exògames que els homes $(31,1 \%)$. Dominicanes, equatorianes, romaneses, senegaleses i xineses s'emparellen més amb espanyols que no pas ells amb espanyoles. A part dels desequilibris en les ràtios per sexe, podem parlar aquí de l'efecte del mercat matrimonial que opera a distància en un context de globalització. El cas pakistanès és particular: s'observa una exogàmia pràcticament inexistent, especialment en les dones. A més dels factors explicatius mencionats, podem afegir-hi el condicionament del patró migratori (marcadament masculí, amb reagrupament de les dones, ja casades) i també factors de caire cultural-religiós (prescripció d'endogàmia religiosa dins l'islam, que portaria a l'endogàmia de país).

Pel que fa a l'efecte del tipus d'unió en la integració, a partir de les dades de l'ENI, s'observen resultats variats: en alguns indicadors d'integració, com l'aprenentatge de les llengües oficials, s'observa una relació positiva pel fet de tenir parella nascuda a Espanya. Així mateix, són les parelles del mateix país d'origen les que menys puntuen en referència a la qualitat de l'habitatge. Però el fet de tenir una parella autòctona no té un efecte clar sobre la mobilitat laboral ascendent o descendent, ni està relacionat amb una major participació 
social. Caldrà fer una anàlisi més acurada per veure si hi ha diferents patrons segons factors com l'origen particular, que ens podrien portar a establir diferents tipologies.

Pel que fa als primers resultats a partir de l'anàlisi descriptiva de xarxes personals, hem analitzat dos perfils socioprofessionals semblants (dones immigrades dominicanes amb nivell d'estudis secundaris, feines en serveis de neteja $\mathrm{i}$ baix nivell d'ingressos); però en el primer cas la seva parella és espanyola (unió mixta) i en el segon cas la seva parella és dominicana (unió endogàmica). El que destaca en ambdós casos és la similitud de la seva xarxa: hi ha pocs o cap familiar de la seva parella; pocs o cap familiar d'origen espanyol; i poca incidència de la parella com a «introductora» d'amics. Per tant, una orientació marcada de totes dues dones cap a les seves comunitats d'origen, resideixin a Espanya o a la República Dominicana, i independentment de si formen una unió mixta o endogàmica. Malgrat que es tracta només de dos casos, i que, per tant, la naturalesa de l'anàlisi és descriptiva més que explicativa, aquests resultats ens obliguen a plantejar-nos si el factor mixt/no-mixt en si mateix és el més rellevant a l'hora d'analitzar les diferències en aquest i altres aspectes de la integració social, o si més aviat cal tenir en compte altres variables (com l'origen específic, la trajectòria migratòria, el nivell socioeconòmic o el sexe/gènere). En alguns casos (no presentats aquí), i amb la informació etnogràfica de conjunt, hem observat també una integració «a la inversa», és a dir, una tendència de la parella espanyola a integrar-se socioculturalment en el món de la parella immigrada.

La informació procedent de les entrevistes en profunditat permetrà interpretar millor la informació quantitativa sobre les xarxes i el capital social (aquí no analitzat), i extreure millors conclusions sobre la causalitat de les relacions.

Pensem que l'ús d'una metodologia mixta o multimètode, que combina l'anàlisi de dades procedents de l'explotació de fonts estadístiques (nivell macro), amb l'anàlisi procedent de la informació sobre les xarxes i el capital social (nivell meso), i amb l'anàlisi de la informació procedent de les entrevistes en profunditat als individus (nivell micro), ha de permetre interpretar millor la informació i extreure conclusions més acurades sobre un tema tan complex.

De moment, tot apunta a una relació entre unió mixta i integració força més complexa del que sovint s'ha teoritzat: no es tracta d'una relació unidireccional, sinó més aviat multidireccional o segmentada, amb diferències segons l'origen o el context social.

\section{Referències bibliogràfiques}

Ajuntament de Barcelona (2012). La població estrangera a Barcelona. Gener 2012. Barcelona: Departament d'Estadística, Ajuntament de Barcelona. Informe estadístic.

Alba, Richard i Kessler, Ronald (1979). «Patterns of Interethnic Marriage Among Catholic Americans». Social Forces, 57, 1.124-1.140.

Arango, Joaquín (2000). "Becoming a Country of Immigration at the End of the Twentieth Century: The Case of Spain». A: King, R.; Lazaridis, G. i TsardaniDIs, C. (eds.). Eldorado o Fortress? Migration in Southern Europe. Londres: Palgrave 
Macmillan, 253-276.

Bastide, Roger (1961). "Dusky Venus, Black Apollo». Race, 3 (1), 10-18. <http://dx.doi.org/10.1177/030639686100300102>

Beck, Ulrich i Beck-Gernsheim, Elisabeth (2012). Amor a distancia. Nuevas formas de vida en la era global. Barcelona: Paidós.

Bотт, Elizabeth (1990) [1957]. Family and Social Network. Londres: Tavistock.

Brandes, Ulrik; Lerner, Jürgen; Lubbers, Miranda J.; McCarty, Cristopher; MoliNA, José Luis i NAGEL, Uwe (2010). «Recognizing modes of acculturation in personal networks of migrants». Procedia. Social and Behavioral Sciences, 4, 4-13. <http://dx.doi.org/10.1016/j.sbspro.2010.07.478>

Bryceson, Deborah i Vuorela, Ulla (eds.) (2002). The Transnational Family: New European Frontiers and Global Networks. Oxford: Berg.

Bueno, Xiana (2010). «Los comportamientos demográficos diferenciales en la formación de la familia de la población inmigrada en España». Bellaterra: Universitat Autònoma de Barcelona Departament de Geografia/Centre d'Estudis Demogràfics. Tesi doctoral.

Coleman, David (1994). «Trends in Fertility and Intermarriage among Immigrant Populations in Western Europe as Measures of Integration». Journal of Biosocial Science, 26 (1), 107-136.

Collet, Beate i Santelli, Emmanuelle (2012). Couples d'ici, parents d'ailleurs. Parcours de descendants d'immigrés. París: PUF. Le Lien Social.

Constable, N. (2003). Romance on a Global Stage. Berkeley: University of California Press.

Cortina, Clara; Esteve, Albert i Domingo, Andreu (2006). "Crecimiento y singularidades demográficas de los matrimonios de extranjeros en España». Migraciones, 20, 75-105.

- (2008). «Marriage Patterns of the Foreign-Born Population in a New Country of Immigration: The Case of Spain». International Migration Review, 42 (4), 877-902. <http://dx.doi.org/10.1111/j.1747-7379.2008.00151.x>

Cortina, Clara; Esteve, Albert i Jiménez, Edurne (2008). «La delicada captación estadística de las uniones de los inmigrantes». Índice, setembre 2008.

Davis, Kingsley (1941). "Intermarriage in Caste Societies». American Anthropologist, 43, 388-395.

Domingo, Andreu (2010). «La immigració i els reptes de futur en la Catalunya del 2030». Quaderns d'Acció Social i Ciutadania, 9. Barcelona: Departament d'Acció Social i Ciutadania, Generalitat de Catalunya.

Doo-Sub, Kim (ed.) (2012). Cross-Border Marriage: Global Trends and Diversity. Seül: KIHASA.

Esteve, Albert i Bueno, Xiana (2010). «Tras el rastro estadístico de las parejas de inmigrantes en España». Revista de Estadistica Española, 52 (173), 91-125.

FANON, Frantz (1967) [1952]. Black skin, white masks. Nova York: Grove.

Fu, Vincent K. (2001) «Racial Intermarriage Pairings». Demography, 38 (2), 147-159. <http://dx.doi.org/10.1353/dem.2001.0011>

Gordon, Milton (1964). Assimilation in American Life. Nova York: OUP.

HeıккILÄ. Elli i Yеон, Brenda (2010). (Eds.) International Marriages in the Time of Globalization. Nova York: Nova Science.

Hull, Kathleen; Meier, Ann i Ortyl, Timothy (2010). «The changing landscape of love and marriage». Contexts, 9 (2), 32-37.

<http://dx.doi.org/10.1525/ctx.2010.9.2.32> 
Idescat (Institut Català d'Estadística) (2009). Moviment natural de la població. Barcelona: Idescat.

INE (Instituto Nacional de Estadística) (2011a). Padrón municipal de población. Madrid: INE.

- (2011b). «Movimiento natural de la población e indicadores demográficos básicos. Año 2010. Datos avanzados». Nota de premsa del 7 de juliol de 2011. Madrid: INE.

Izquierdo Escribano, Antonio (1996). La inmigración inesperada. La población extranjera en España (1991-1995). Madrid: Trotta.

Kalmijn, Matthijs (1998). "Intermarriage and Homogamy: Causes, Patterns and Trends». Annual Review of Sociology, 24, 395-421. <http://dx.doi.org/10.1146/annurev.soc.24.1.395>

- (2010). «Educational inequality, homogamy and status exchange in Black-White intermarriage: A comment on Rosenfeld». American Journal of Sociology, 115 (4), 1.252-1.263. <http://dx.doi.org/10.1086/649050>

KING, Russell (2002). "Towards a New Map of European Migration». International Journal of Population Geography, 8 (2), 89-106. <http://dx.doi.org/10.1002/ijpg.246>

LeACH, Edmund (1967). "Characterization of Caste and Race Systems». A: De Reuck, A. i Knight, J. (eds.). Caste and Race: Comparative Approaches. Londres: Ciba Foundation Symposia, 17-27.

LeE, Sara (2004) «Marriage Dilemmas: Partner Choices and Constraints for Korean Americans in New York City». A: Lee, J. i Zhou, M. (eds.) Asian American Youth. Culture, Identity and Ethnicity. Londres i Nova York: Routledge, 285-298.

Lieberson, S. i Waters, Mary C. (1988). From Many Strands: Ethnic and Racial Groups in Contemporary America. Nova York: Russell Sage.

Lievens, John (1999). "Family-Forming Migration from Turkey and Morocco to Belgium». International Migration Review, 33 (3), 717-744. <http://dx.doi.org/10.2307/2547532>

Lubbers, Miranda J.; Molina, José Luis; McCarty, Cristopher (2007). «Personal Networks and Ethnic Identifications: The Case of Migrants in Spain». International Sociology, (22), 721-741.

MaI, Nicola i KIng, Rusell (2009). «Love, sexuality and migration: mapping the issue(s)». Mobilities, 4 (3): 295-307. <http://dx.doi.org/10.1080/17450100903195318>

Marcson, Simon (1950). A theory of intermarriage and assimilation. Social Forces, 29 (1), 75-78. <http://dx.doi.org/10.2307/2572762>

McCarty, Cristopher (2002). «Structure in Personal Networks». Journal of Social Structure. <http://www.cmu.edu/joss/content/articles/volume3/McCarty.html> [consulta: 10 d'octubre de 2013].

McCarty, Cristopher; Molina, José Luis; Aguilar, Claudia i Rota, Laura (2007). "A Comparison of Social Network Mapping and Personal Network Visualization». Field Methods, 19 (2), 145-162. <http://dx.doi.org/10.1177/1525822X06298592>

Merton, Robert K. (1941). «Intermarriage and the Social Structure: Fact and Theory». Psychiatry, 4, 361-374.

Miguel Luken, Verónica de; Rodríguez-García, Dan; Solana Solana, Miguel i Pascual de SAns, Àngels (2012). La població immigrada a Catalunya: consideracions sobre les seves condicions d'assentament $i$ integració a partir de les dades de l'ENI 
2007. Barcelona: Institut d'Estudis Catalans.

Miguel Luken, Verónica de; Solana Solana, Miguel i Pascual de Sans, Àngels (dir.) (2007). Redes sociales de apoyo. La inserción de la población extranjera. Bilbao: BBVA.

Molina, José Luis; McCarty, Cristopher; Aguilar, Claudia i Rota, Laura (2007). "La estructura social de la memoria». A: LozAres, C. (ed.). Interacción, redes sociales y ciencias cognitivas. Barcelona: La Razón Áurea.

Pagnini, Deanna i Morgan, S. Phillip (1990). "Intermarriage and social distance among U.S. immigrants at the turn of the century». American Sociological Review, 96, 405-432.

<http://dx.doi.org/10.1086/229534>

Penninx, Rinus (2005). «Integration of migrants: economic, social, cultural and political dimensions». A: Macura, M.; MacDonald, A. i Haug, W. (eds.). The new demographic regime. Population challenges and policy responses. Nova York / Ginebra: United Nations, 137-152.

Porter, John (1965). The Vertical Mosaic: An Analysis of Social Class and Power in Canada. Toronto: UTP.

Qian, Z. i Lichter, D. (2001). «Measuring Marital Assimilation: Intermarriage among Natives and Immigrants». Social Science Research, 30, 289-312. <http://dx.doi.org/10.1006/ssre.2000.0699>

RESNIK, Reuben B. (1933). «Some sociological aspects of intermarriage of Jew and non-Jew». Social Forces, 12 (1), 94-102. <http://dx.doi.org/10.2307/2570123>

Roca Girona, Jordi (2011). «Amores glocales, noviazgos transnacionales. La búsqueda virtual de pareja mixta por parte de hombres españoles». Revista de Antropología Social, 20, 263-292.

Rodríguez-García, Dan (2002). «Endogamia, exogamia y relaciones interétnicas. Un estudio sobre la formación y dinámica de la pareja y la familia centrado en inmigrantes de Senegal y Gambia en Cataluña». Bellaterra: Universitat Autònoma de Barcelona. Departament d'Antropologia Social i Cultural. Tesi doctoral.

- (2004a). Inmigración y mestizaje hoy. Formación de matrimonios mixtos y familias transnacionales de población africana en Cataluña. Barcelona: Servei de Publicacions de la UAB.

- (2004b). «Inmigración y mestizaje hoy. Formación de matrimonios mixtos y familias transnacionales de inmigrantes en Cataluña». Migraciones, 16, 77-120.

- (2006). «Mixed Marriages and Transnational Families in the Intercultural Context». Journal of Ethnic and Migration Studies, 32 (3), 403-433. <http://dx.doi.org/10.1080/13691830600555186>

- (2007). "Intermarriage Patterns and Socio-ethnic Stratification among Ethnic Groups in Toronto». CERIS Working Paper No. 60. Toronto: CERIS - Joint Centre of Excellence for Research on Immigration and Settlement.

- (2012). «Considérations théoricométhodologiques autour de la mixité». Enfances, Familles, Générations, 17, 41-58 (núm. especial: «Mixité conjugale et définition de soi: regards croisés»).

Rosenfeld, Michael (2005). "A Critique of Exchange Theory in Mate Selection». American Journal of Sociology, 110 (5), 1.284-1.325. <http://dx.doi.org/10.1086/428441>

- (2007). The Age of Independence: Interracial Unions, Same-Sex Unions, and the Changing American Family. Cambridge: Harvard University Press.

Rumbaut, Rubén G. (1997). «Assimilation and its Discontents: Between Rhetoric 
and Reality». International Migration Review, 31 (4), 923-960. <http://dx.doi.org/10.2307/2547419>

Rytina, Steve; Blau, Peter; Blum, Terry; Schwartz, Josehp (1988). «Inequality and Intermarriage: A paradox of Motive and Constraint», Social Forces, 66: 645-675.

SAFI, Mirna (2006). «Le processus d'intégration des immigrés en France: inégalités et segmentation». Revue Française de Sociologie, 62 (3), 618-639.

- (2008). «Intermarriage and assimilation: disparities in levels of exogamy among immigrants in France». Population, 63 (2), 239-268.

<http://dx.doi.org/10.3917/pope.802.0239>

SAID, Edward (1978). Orientalism. Nova York: Vintage.

Sánchez Domínguez, María Isabel (2011). «Estrategias matrimoniales y procesos de integración social de los inmigrantes en España». Madrid: Universidad Complutense de Madrid. Tesi doctoral.

Santacreu, Óscar i Francés, Francisco (2008). «Parejas mixtas de europeos en España: integración, satisfacción y expectativas de futuro». Obets, 1, 7-20. <http://dx.doi.org/10.14198/OBETS2008.1.01>

Scott, Sam; Cartledge, Kim H. (2009). «Migrant Assimilation in Europe: A Transnational Family Affair». International Migration Review, 43 (1), 60-89. <http://dx.doi.org/10.1111/j.1747-7379.2008.01147.x>

Song, Miri (2009). «Is Intermarriage a Good Indicator of Integration?». Journal of Ethnic and Migration Studies, 35 (2), 331-348. <http://dx.doi.org/10.1080/13691830802586476>

- (2010). "What happens after segmented assimilation? An exploration of intermarriage and 'mixed race' young people in Britain». Ethnic and Racial Studies, 33 (7), 1.194-1.213. <http://dx.doi.org/10.1080/01419871003625271>

Song, Miri i Aspinall, Peter (2012). «Is racial mismatch a problem for young 'mixed race' people in Britain? The findings of qualitative research». Ethnicities, 12 (2), $1-24$.

Waldis, Barbara; Byron, Reginald (2006) (eds.) Migration and Marriage Heterogamy and Homogamy in a Changing World. Zuric: LIT.

WARD, Colleen (2013). «Probing identity, integration and adaptation: Big questions, little answers Original». International Journal of Intercultural Relations, 37 (4), 391-404. <http://dx.doi.org/10.1016/j.ijintrel.2013.04.001>

Wellman, Barry; Berkowitz, Stephen (eds.) (1988). Social Structures: A Network Approach. Cambridge: Cambridge University Press.

Williams, Lucy (2010). Global Marriage: Cross-Border Marriage Migration in Global Context. Basingstoke, Nova York: Palgrave Macmillan. <http://dx.doi.org/10.1057/9780230283022> 